\title{
Clinical Impact of the Bronchiectasis with Chronic Bronchitis Symptoms in COPD: Analysis of a Longitudinal Cohort
}

\author{
Eun Kyung Kim (D) \\ Mi-Ae Kim' \\ Jae Seung Lee ${ }^{2}$ \\ Sang Min Lee $\mathbb{D}^{3}$ \\ Soyeoun $\operatorname{Lim} \mathbb{1}^{4}$ \\ Jisoo Park (D) \\ Jung-Hyun Kim' \\ Yeon-Mok Oh (iD ${ }^{2}$ \\ Sang-Do Lee ${ }^{2}$ \\ Se Hee Lee' \\ ji-Hyun Lee ${ }^{\prime}{ }^{\prime}$
}

\section{On behalf of the KOLD Study Group}

'Department of Pulmonology, Allergy and Critical Care Medicine, $\mathrm{CHA}$ Bundang Medical Center, CHA University, Seongnam, Republic of Korea; ${ }^{2}$ Department of Pulmonary and Critical Care Medicine, Asan Medical Center, University of Ulsan College of Medicine, Seoul, Republic of Korea; ${ }^{3}$ Department of Radiology, Asan Medical Center, University of Ulsan College of Medicine, Seoul, Republic of Korea; ${ }^{4}$ Department of Radiology, Ulsan University Hospital, University of Ulsan College of Medicine, Ulsan, Republic of Korea
Correspondence: Ji-Hyun Lee Department of Pulmonology, Allergy and Critical Care Medicine, CHA Bundang Medical Center, CHA University, 59 Yatap-ro, Bundang-gu, Seongnam, I3496, Republic of Korea

Tel +82-3I-780-5205

$\mathrm{Fax}+82-3 \mathrm{I}-780-2992$

Email plmjhlee@cha.ac.kr
Purpose: Bronchiectasis (BE) is a poor prognostic factor in COPD. However, it is not clear whether the poor prognosis is a result of $\mathrm{BE}$ alone or accompanying chronic bronchitis symptoms. Therefore, we investigated the effect of chronic bronchitis symptoms on clinical outcomes in COPD patients with BE.

Patients and Methods: We analyzed data of COPD patients from the Korean Obstructive Lung Disease (KOLD) cohort. The presence of BE was verified by chest computed tomography. Chronic bronchitis symptoms were determined using items in the symptomatic domain of the SGRQ, which is also used as an alternative definition of chronic bronchitis (CB). Patients were divided into four groups according to the presence of $\mathrm{BE}$ and $\mathrm{CB}$ symptoms: $\mathrm{BE} / \mathrm{CB}, \mathrm{BE}-$ only, $\mathrm{CB}-$ only, and no BE/CB. Demographic features and clinical outcomes were compared among these groups.

Results: In total, 389 COPD patients were included in the analysis. BE was present in 148 (38\%) patients and $\mathrm{CB}$ symptoms were found in 123 patients (33.2\%). The patients were divided according to $\mathrm{BE}$ and $\mathrm{CB}$ symptoms, and the numbers and percentages of each group were as follows: $\mathrm{BE} / \mathrm{CB}$, 52 (13.4\%); BE-only, 96 (24.7\%); CB-only, 77 (19.8\%); no BE/CB, 164 (42.2\%). No significant differences were observed in baseline characteristics of lung function, radiological findings, and inflammatory markers among the four groups. The proportion of annual exacerbators was higher in the $\mathrm{BE} / \mathrm{CB}$ and $\mathrm{CB}$-only groups than the other two groups. After adjusting other parameters, the $\mathrm{BE} /$ $\mathrm{CB}$ group was significantly associated with acute exacerbation of COPD (AE-COPD) $(\mathrm{OR}=2.110$, $\mathrm{p}=0.045)$.

Conclusion: $\mathrm{BE}$ accompanying $\mathrm{CB}$ symptoms is associated with $\mathrm{AE}-\mathrm{COPD}$, while $\mathrm{BE}$ alone was not significantly associated. This finding suggests that it is more important to examine chronic bronchitis symptoms of $\mathrm{BE}$ to predict acute exacerbation than simply to identify BE in COPD patients.

Keywords: COPD, bronchiectasis, chronic bronchitis, exacerbation

\section{Introduction}

Chronic obstructive pulmonary disease (COPD) is a heterogeneous disease caused by chronic airway and systemic inflammation, accompanied by several comorbid conditions. $^{1,2}$

With the widespread use of chest computed tomography (CT), the reported detection rate of coexisting bronchiectasis $(\mathrm{BE})$ varies between $15 \%$ and $69 \%$ in patients with moderate to severe COPD. ${ }^{3-6}$ The coexistence of $\mathrm{BE}$ is an independent factor associated with poor prognosis in COPD in terms of acute exacerbation ${ }^{3,7,8}$ and mortality. ${ }^{3,9}$ 
However, some studies have reported no significant associations of BE with COPD exacerbations. ${ }^{10,11}$

Representative symptoms of $\mathrm{BE}$ are chronic cough and sputum, which are also typical clinical presentations of chronic bronchitis (CB). Symptoms of CB are related to poorer healthrelated quality of life, ${ }^{12-14}$ accelerated decline in lung function, ${ }^{12,15-17}$ and increased mortality, ${ }^{14,18,19}$ as well as greater number and severity of COPD exacerbations. ${ }^{20}$ Additionally, even in the general population, symptoms of chronic cough and sputum are among the substantial risk factors for developing airflow limitation and/or COPD. ${ }^{21,22}$

In these contexts, it is reasonable to doubt whether the poorer prognosis in COPD patients with $\mathrm{BE}$ is caused by the accompanying $\mathrm{CB}$ symptoms or BE per se.

$\mathrm{BE}$ is a heterogeneous disease with various clinical manifestations. In a recent cluster analysis of BE, four different clusters were identified as "Pseudomonas," "Other chronic infection," "Daily sputum," and "Dry BE". ${ }^{23}$ In cluster analysis, clinical symptoms and bacterial colonization are important parameters to determine the clinical phenotype of BE, which is associated with quality of life, exacerbations, hospitalization, and death. Especially, the "Dry BE" phenotype, with a rate of $27 \%$ in the study population, had better lung function and prognosis than the others.

We hypothesized that the prognosis may be different according to the presence of symptoms in COPD patients with coexisting BE. Therefore, we investigated the effects of CB symptoms on clinical outcomes in COPD patients with $\mathrm{BE}$ in our longitudinal cohort.

\section{Materials and Methods Study Design}

\section{Patients}

This study was carried out with the Korean Obstructive Lung Disease (KOLD) cohort, which enrolled 477 COPD patients on an outpatient basis from pulmonary clinics in 16 hospitals throughout South Korea between June 2005 and April 2014. From this KOLD cohort, 389 COPD patients were selected according to the following four criteria: post-bronchodilator ratio of forced expiratory volume in $1 \mathrm{~s}\left(\mathrm{FEV}_{1}\right)$ to forced vital capacity (FVC) $<0.7$ after administration of $400 \mu \mathrm{g}$ of inhaled albuterol; smoking history $>10$ pack-years; no or minimal abnormalities on chest radiography; and availability of chest $\mathrm{CT}$ at baseline.

\section{Clinicophysiological Indices of COPD}

Demographic and clinical data were collected, including age, sex, smoking status, history of exacerbations, etc. Dyspnea was assessed using the Modified Medical Research Council (mMRC) Dyspnea scale ${ }^{24}$ and the health-related quality of life was assessed using the St. George Respiratory Questionnaire (SGRQ). ${ }^{25}$ Spirometry was performed using Vmax 22 (SensorMedics, Yorba Linda, CA, USA; and PFDX instrument; MedGraphics, St. Paul, MN, USA) according to the guidelines of the American Thoracic Society. ${ }^{26}$ Medication history, smoking status, mMRC score, and acute exacerbation history were obtained at each visit. COPD medications were defined as inhaled corticosteroid/ long acting $\beta-2$ agonist (ICS/LABA), long-acting muscarinic antagonist (LAMA), or others according to the prescription for more than two-thirds of the study period.

Spirometry was performed at 6-month intervals; diffusion capacity, lung volume, 6-minute walking distance (6MWD), and SGRQ score were determined annually. The emphysema index (EI), airway wall area percentage (AWA\%), and air-trapping index (ATI) were determined from chest $\mathrm{CT}$ data, as reported previously. ${ }^{27}$

\section{Detection of $B E$}

All patients were in a stable condition at the time of CT and none had experienced an exacerbation. Two radiologists who were unaware of the patients' clinical condition participated in radiological interpretation of the CT scans for the presence, severity, radiological pattern, and distribution of BE; associated disease findings, such as emphysema and small airway diseases; and others. The presence of BE was based on the criteria published by Naidich et al. Lack of tapering of bronchi; dilation of bronchi when the internal diameter was larger than that of the adjacent pulmonary artery; or visualization of the peripheral bronchi within $1 \mathrm{~cm}$ of the costal pleural surface or adjacent mediastinal pleural surface. ${ }^{28}$ In addition to assessing the type of BE (cylindrical, varicose, cystic), the severity of $\mathrm{BE}$ was evaluated using the modified Bhalla score., ${ }^{8,29}$

\section{Defining Symptoms of Chronic Bronchitis and Classification of Patient Groups}

Presence of the CB symptoms was evaluated by using items in the symptomatic domain of the SGRQ questionnaire. ${ }^{30,31}$ Two questions inquire about symptoms of cough and sputum within one month, and these may be used as alternatives to investigations based on the classical definition. 1) How often do you complain of cough during the week? 2) How often do you complain of sputum production during the week? Patients who answered "most days of the week" or "several days of the week" to both of these questions were considered to have 
CB. ${ }^{30,31}$ Finally, we divided the patients into four groups according to the presence of $\mathrm{BE}$ and symptoms of $\mathrm{CB}: \mathrm{BE} /$ $\mathrm{CB}\left(\mathrm{BE}+/ \mathrm{CB}^{+}\right)$, BE-only $\left(\mathrm{BE}^{+} / \mathrm{CB}^{-}\right)$, CB-only $\left(\mathrm{BE}-/ \mathrm{CB}^{+}\right)$, and no $\mathrm{BE} / \mathrm{CB}\left(\mathrm{BE}-/ \mathrm{CB}^{-}\right)$groups.

\section{Analysis of Clinical Outcomes of COPD}

Acute exacerbation of COPD (AE-COPD) was defined as an acute worsening of respiratory symptoms (dyspnea, cough, or sputum) requiring additional therapy. ${ }^{1,2,32}$ Severe AE-COPD was defined as hospitalization or visiting the emergency department due to worsening of COPD. ${ }^{1,2}$ The annual incidences of AE-COPD and severe AE-COPD were calculated by dividing total exacerbation number by follow-up duration. An annual exacerbator was defined when a COPD patient who experienced $\geq 1$ exacerbations per year (annual incidence of AECOPD $\geq 1$ ). A frequent exacerbator was defined as $\geq 2$ exacerbations or $\geq 1$ severe exacerbations per year. Annual decline in post-bronchodilator $\mathrm{FEV}_{1}$ was analyzed. Mortality data were collected during the follow-up period.

\section{Statistical Analysis}

All data were analyzed with SPSS 21.0 (IBM Corp., Armonk, NY, USA). Categorical data are described as number (percentage) and continuous variables are expressed as means \pm standard deviation. We analyzed the clinical characteristics of the four groups with the Chisquare test and one-way analysis of variance (ANOVA) with Bonferroni post hoc analysis for categorical and continuous variables, respectively. Clinical characteristics were compared using Student's $t$ test for continuous data and the Chi-square test for categorical data. Annual decline in post-bronchodilator $\mathrm{FEV}_{1}$ was analyzed by random-slope and random-intercept mixed linear regression as described previously. ${ }^{33}$ Association analyses were performed using Pearson's correlation coefficient among continuous data and logistic regression analysis when dependent data were categorical. Kaplan-Meier and Cox proportional hazard ratio analyses were conducted to evaluate time to exacerbation and mortality. In all analyses, $p<0.05$ was taken to indicate statistical significance.

\section{Ethics Statement}

The study protocol was approved by the institutional review board of the Asan Medical Center (Approval No. 2005-0345) and the 16 other participating hospitals. Written informed consent was obtained from all patients.

\section{Results}

\section{Baseline Characteristics}

In total, 389 COPD patients from the KOLD cohort who fulfilled the inclusion criteria were included in the study (Figure 1). Baseline characteristics are presented in Table 1 patients had a mean age of $66.9 \pm 7.4$ years, $97.7 \%$ were male, and $29.0 \%$ were current smokers. The mean post-bronchodilator $\mathrm{FEV}_{1}$ was $54.1 \% \pm 16.1 \%$, the median follow-up time was 6.8 years, and the mean

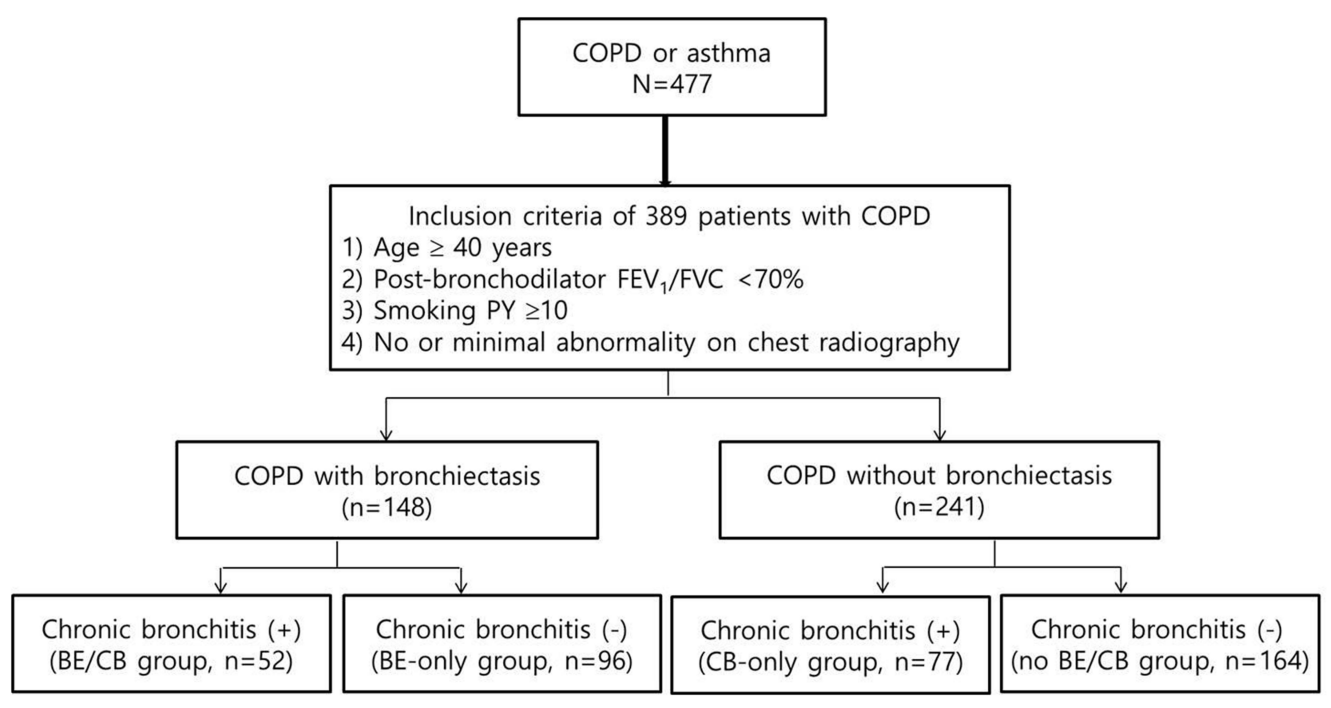

Figure I Flow diagram of enrollment.

Abbreviations: $\mathrm{BE}$, bronchiectasis; $\mathrm{CB}$, chronic bronchitis; $\mathrm{COPD}$, chronic obstructive pulmonary disease; $\mathrm{FEV}$, forced expiratory volume in I second; FVC, forced vital capacity; PY, pack-years. 
Table I Baseline Characteristics of the Subjects

\begin{tabular}{|c|c|}
\hline Parameter $(\mathrm{N}=389)$ & Mean \pm SD, n (\%) \\
\hline Age (years) & $66.9 \pm 7.4$ \\
\hline Male & $380(97.7)$ \\
\hline Smoking amount (pack-year) & $45.9 \pm 26.2$ \\
\hline Current smoker & II $3(29.0)$ \\
\hline BMI $\left(\mathrm{kg} / \mathrm{m}^{2}\right)$ & $23.0 \pm 3.2$ \\
\hline 6MWD (m) & $427.8 \pm 86.0$ \\
\hline Dyspnea (mMRC) & $1.7 \pm 1.1$ \\
\hline SGRQ & $32.8 \pm 17.6$ \\
\hline Charlson's comorbidity score & $1.30 \pm 0.67$ \\
\hline The presence of $\mathrm{BE}$ & $148(38.0)$ \\
\hline The presence of $C B$ & $129(33.2)$ \\
\hline \multicolumn{2}{|l|}{ Lung function } \\
\hline Pre BD FVC (\% predicted) & $78.1 \pm 16.4$ \\
\hline Post BD FVC (\% predicted) & $83.1 \pm 15.9$ \\
\hline Pre BD FEV (\% predicted) & $48.9 \pm 15.5$ \\
\hline Post BD FEV ( (\% predicted) & $54.1 \pm 16.1$ \\
\hline $\mathrm{FEV}_{1} / \mathrm{FVC}(\%)$ & $46.8 \pm 11.1$ \\
\hline DLco (\% predicted) & $77.3 \pm 23.9$ \\
\hline $\mathrm{FEV}$, decline $(\mathrm{mL} /$ year, $\mathrm{n}=34 \mathrm{I})$ & $-24.73 \pm 24.65$ \\
\hline \multicolumn{2}{|l|}{ Medications $(n=359)$} \\
\hline ICS/LABA & $196(54.6)$ \\
\hline LAMA & $151(42.1)$ \\
\hline Other medications* & $12(3.3)$ \\
\hline \multicolumn{2}{|l|}{ Radiologic findings } \\
\hline Emphysema index (\%) & $21.7 \pm 15.3$ \\
\hline Airway Wall area (\%) & $17.6 \pm 3.5$ \\
\hline Air-trapping index & $0.95 \pm 0.03$ \\
\hline \multicolumn{2}{|l|}{ Blood laboratory findings } \\
\hline Leukocyte $\left(\times 10^{3} / \mu \mathrm{L}\right)$ & $7.3 \pm 2.0$ \\
\hline Blood eosinophils (cells $/ \mu \mathrm{L}$ ) & $273.6 \pm 321.4$ \\
\hline Hemoglobin (g/dL) & $14.9 \pm 1.3$ \\
\hline Platelet $\left(\times 10^{3} / \mu \mathrm{L}\right)$ & $239.2 \pm 62.4$ \\
\hline Protein $(g / d L)$ & $7.1 \pm 0.5$ \\
\hline Albumin $(g / d L)$ & $4.2 \pm 0.4$ \\
\hline Cholesterol (mg/dL) & $171.9 \pm 61.5$ \\
\hline $\mathrm{Hs}-\mathrm{CRP}(\mathrm{mg} / \mathrm{dL})$ & $0.4 \pm 1.0$ \\
\hline Creatinine (mg/dL) & $1.0 \pm 0.2$ \\
\hline
\end{tabular}

Notes: Data are presented as $n(\%)$ or mean \pm SD. *Other medications, ICS $(n=6)$, LABA [Onbrez ${ }^{\circledR}$ (indacaterol), $\left.n=5\right]$, Combivent ${ }^{\circledR}$ (ipratropium bromide/salbutamol, $n=1)$.

Abbreviations: SD, standard deviation; BMI, body mass index; 6MWD, 6-minute walk distance; mMRC, modified Medical Research Council; SGRQ, St. George's Respiratory Questionnaire; BD, bronchodilator; $\mathrm{BE}$, bronchiectasis; $\mathrm{CB}$, chronic bronchitis; $\mathrm{FEV}_{\mathrm{I}}$, forced expiratory volume in I second; FVC, forced vital capacity; DLco, diffusing capacity of the lung for carbon monoxide; ICS, inhaled corticosteroid; LABA, long acting $\beta 2$-agonist; LAMA, long acting muscarinic antagonist; hs-CRP, high-sensitivity C-reactive protein.
mMRC and SGRQ scores were $1.7 \pm 1.1$ and $32.8 \pm 17.6$, respectively.

BE was detected on chest CT in 148 (38\%) patients. Agreement between the two radiologists was good in terms of detecting and scoring BE (Kappa index, 0.88) [intraclass correlation coefficient (ICC), $0.975(95 \% \mathrm{CI}$ $=0.969-0.979, p<0.001)]$. The median modified Bhalla score was 9.5 in patients with BE (range: 6.5-14.6) (Supplementary Table 1). CB symptoms were present in $33.2 \%$ of the total COPD patient population.

\section{Comparison of Clinical Characteristics According to BE and CB Symptoms}

About $35 \%$ of COPD patients with BE (52/148) had symptoms of $\mathrm{CB}$ and the patients were divided into the following four groups: $\mathrm{BE} / \mathrm{CB}(\mathrm{n}=52,13.4 \%)$, BE-only $(\mathrm{n}=96$, $24.7 \%)$, CB-only $(\mathrm{n}=77,19.8 \%)$, and no $\mathrm{BE} / \mathrm{CB}(\mathrm{n}=164$, $42.2 \%$ ). Clinical characteristics of each group are presented in Table 2. Those in the BE/CB and CB-only groups were more likely to be current smokers and had higher mMRC scores compared to those in the BE-only and no $\mathrm{BE} / \mathrm{CB}$ groups. The $\mathrm{BE} / \mathrm{CB}$ group had a lower BMI compared to the $\mathrm{CB}$-only and no $\mathrm{BE} / \mathrm{CB}$ groups and higher mMRC and SGRQ scores compared to the BE-only and no BE/CB groups. The $\mathrm{BE} / \mathrm{CB}$ and $\mathrm{BE}$-only groups had shorter $6 \mathrm{MWD}$ than the CB-only group (Table 2).

Lung function and radiographic findings of EI, AWA\%, and ATI did not differ among the four groups. The annual decline in lung function (post-bronchodilator $\mathrm{FEV}_{1}$ ) did not show any difference among the groups. We were able to obtain medication history in 359 of the 389 patients. The proportion of patients who used ICS/LABA or LAMA during the follow-up was similar among the four groups. Inflammatory markers, including blood leukocyte count, blood eosinophil count and high-sensitivity C-reactive protein (hs-CRP) level, did not differ among the groups (Table 2).

We divided the total patient population into two groups according to the presence $(n=148)$ or absence of BE $(n=$ 241); COPD patients with BE had lower BMI and shorter 6MWD than those without BE. No differences were observed in terms of lung function, dyspnea, quality of life, or $\mathrm{FEV}_{1}$ decline according to BE (Supplementary Table 1). In other words, the presence of $\mathrm{BE}$ alone did not have a serious impact on the severity of COPD. No significant differences were observed in the types (cylindrical, varicose, or cystic) and severity (modified Bhalla 


\begin{tabular}{|c|c|c|c|c|c|c|c|c|c|c|c|c|c|}
\hline 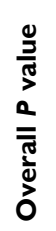 & $\begin{array}{l}\tilde{n} \\
\tilde{O} \\
0\end{array}$ & $\stackrel{\substack{0 \\
0}}{0}$ & $\underset{0}{\infty}$ & రి & $\bar{o}$ & $\begin{array}{l}\tilde{T} \\
0 \\
0\end{array}$ & $\frac{8}{0}$ & $\frac{N}{0}$ & $\bar{\delta}$ & 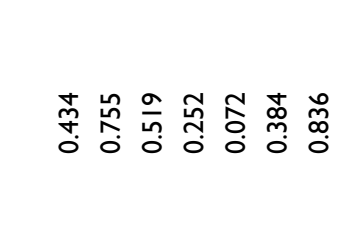 & 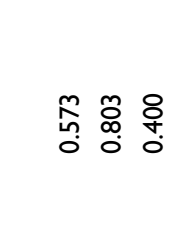 & त्र̂े & 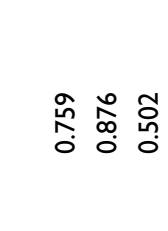 \\
\hline 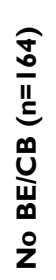 & 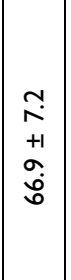 & $\begin{array}{l}\widehat{\overline{\dot{\alpha}}} \\
\stackrel{0}{\circ} \\
\stackrel{\circ}{\circ}\end{array}$ & 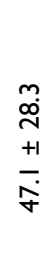 & $\begin{array}{l}\widehat{o} \\
\stackrel{d}{d} \\
\bar{\sigma}\end{array}$ & $\mid \begin{array}{c}m \\
m \\
+1 \\
\omega \\
\tilde{n} \\
\tilde{n}\end{array}$ & $\mid \begin{array}{c}0 \\
\infty \\
\infty \\
+1 \\
+1 \\
\stackrel{j}{\tilde{\sigma}} \\
\tilde{\sigma}\end{array}$ & $\begin{array}{l}\mathfrak{n} \\
\stackrel{+}{ } \\
++1 \\
\stackrel{n}{\longrightarrow}\end{array}$ & 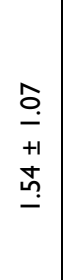 & 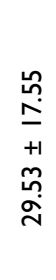 & 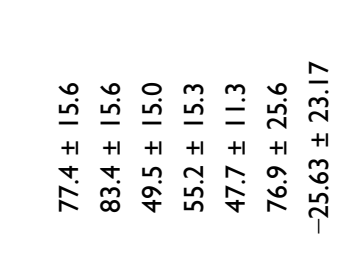 & 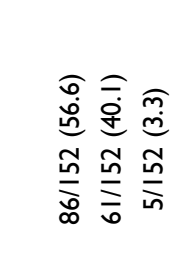 & 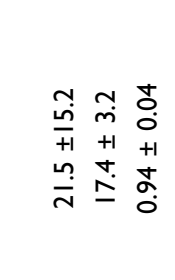 & 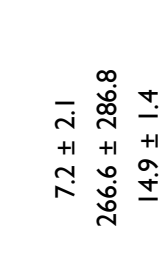 \\
\hline 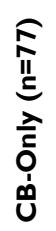 & $\begin{array}{c}+ \\
\infty \\
+1 \\
m \\
n \\
0 \\
\omega\end{array}$ & $\begin{array}{l}\widetilde{u} \\
\stackrel{0}{0} \\
\text { N }\end{array}$ & 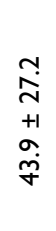 & 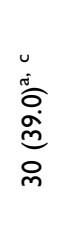 & $\mid \begin{array}{c}0 \\
i \\
+1 \\
+ \\
\dot{v} \\
\sim\end{array}$ & $\mid \begin{array}{l}0 \\
\dot{2} \\
+1 \\
m \\
0 \\
j \\
j \\
j\end{array}$ & 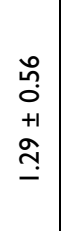 & 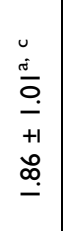 & 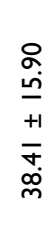 & 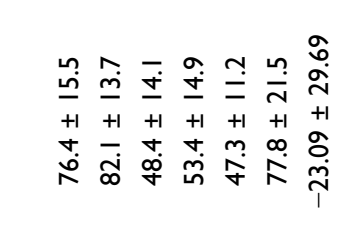 & 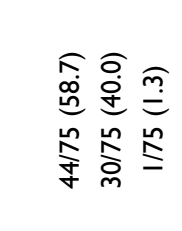 & 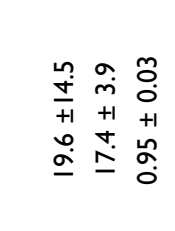 & 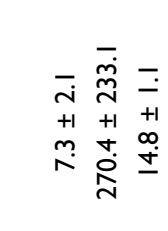 \\
\hline 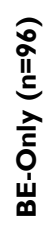 & $\begin{array}{l}\stackrel{\sim}{\sim} \\
\dot{0} \\
+1 \\
\sim \\
\infty \\
0 \\
0\end{array}$ & 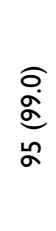 & $\begin{array}{l}\infty \\
\stackrel{\infty}{\sim} \\
+1 \\
m \\
j \\
\dot{j}\end{array}$ & $\begin{array}{l}\widetilde{a} \\
\mathbb{d} \\
\tilde{N}\end{array}$ & 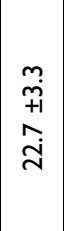 & $\mid \begin{array}{c}0 \\
0 \\
\infty \\
o \\
+1 \\
\infty \\
\infty \\
\dot{\sigma} \\
\dot{\sigma} \\
\end{array}$ & $\begin{array}{l}\stackrel{\circ}{0} \\
\vdots \\
++1 \\
m \\
\mathfrak{m} \\
-\end{array}$ & 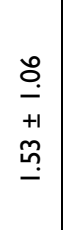 & 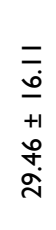 & 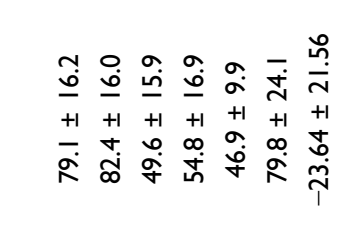 & 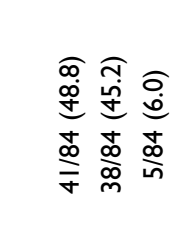 & 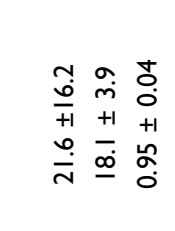 & 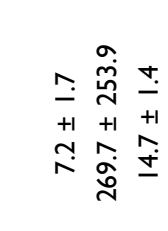 \\
\hline 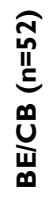 & $\begin{array}{l}\sigma \\
\mathfrak{r} \\
+1 \\
+1 \\
0 \\
0\end{array}$ & 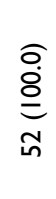 & 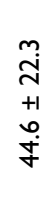 & $\begin{array}{l}0 \\
0 \\
0 \\
0 \\
0 \\
e \\
0 \\
0\end{array}$ & 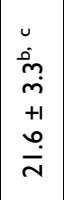 & 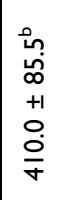 & 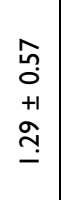 & 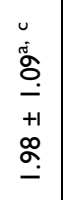 & 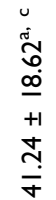 & 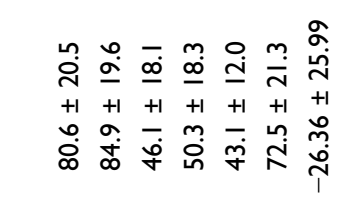 & 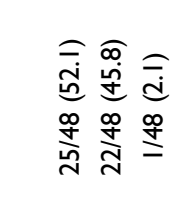 & 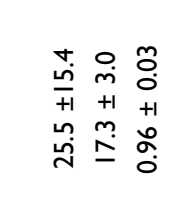 & 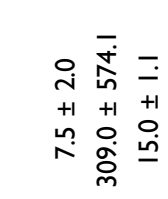 \\
\hline 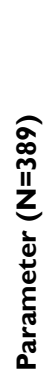 & 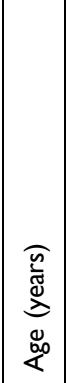 & $\frac{\frac{\omega}{N \sigma}}{\Sigma}$ & 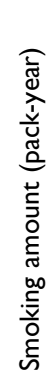 & 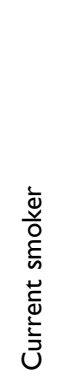 & 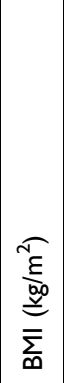 & 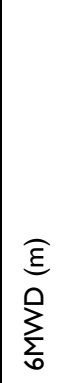 & 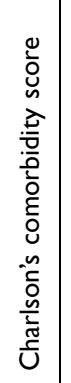 & 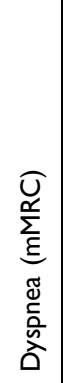 & 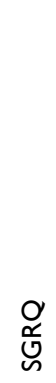 & 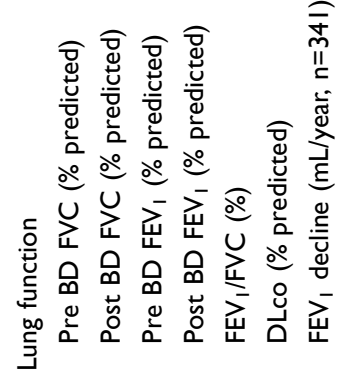 & 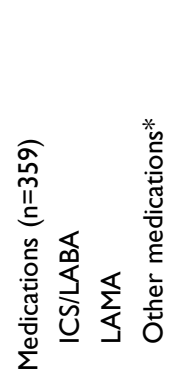 & 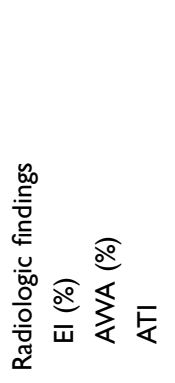 & 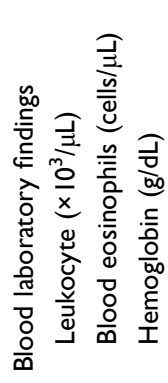 \\
\hline
\end{tabular}




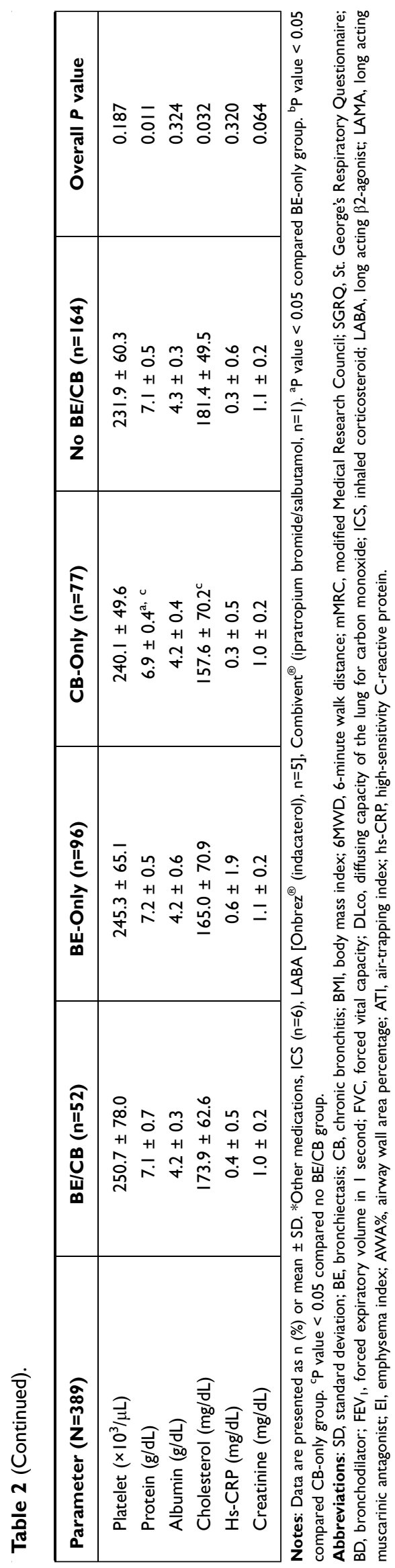

score) of $\mathrm{BE}$ according to $\mathrm{CB}$ symptoms $(p=0.805)$ (Supplementary Table 2).

\section{Comparison of Exacerbations of COPD According to BE and CB Symptoms}

The median follow-up (interquartile range) was 6.83 (3.17-10.53) years. During the follow-up period, AECOPD and severe AE-COPD occurred in $61.4 \%$ and $23.4 \%$ of the entire population, respectively; 114 (29.3\%) were annual exacerbators ( $\mathrm{AE} \geq 1$ per one year) and 54 $(13.9 \%)$ were frequent exacerbators. Table 3 compares exacerbation and death rates among the four groups. A history of AE-COPD in the previous year was found in $20.1 \%$ of the total patient population. The incidence of AE-COPD in the previous year was higher in the BE/CB group than the $\mathrm{BE}-$ only and no $\mathrm{BE} / \mathrm{CB}$ groups. The annual incidence of AE-COPD and severe AE-COPD did not differ among groups $(p=0.545, p=0.224$, respectively, Table 3). The proportion of annual exacerbators was higher in the $\mathrm{BE} / \mathrm{CB}$ group than the $\mathrm{BE}$-only group ( $p=$ $0.037)$ and no $\mathrm{BE} / \mathrm{CB}$ group $(p=0.033)$ (Figure 2$)$.

Of the 148 patients with $\mathrm{BE}$, the proportion of annual exacerbators was higher in the $\mathrm{BE} / \mathrm{CB}$ group than the $\mathrm{BE}-$ only group $(40.4 \%$ vs $24.0 \%$, respectively, $p=0.037$, Table 3). Time to the first COPD exacerbation was shorter and the exacerbation risk was higher in the $\mathrm{BE} / \mathrm{CB}$ group than the BE-only group (Supplementary Figure 1).

Logistic regression analysis was performed to analyze risk factors for annual exacerbation of COPD (exacerbations/year $\geq 1$ ). Blood eosinophil count, hs-CRP level, the presence of $\mathrm{BE}$, type of $\mathrm{BE}$, and modified Bhalla score were not associated with annual AE-COPD. Table 4 lists the data: after adjusting other variables, including age, $\mathrm{BMI}, \mathrm{FEV}_{1}, \mathrm{mMRC}$, and $\mathrm{EI}$, the $\mathrm{BE} / \mathrm{CB}$ group had a significant association with annual AE-COPD ( $p=$ $0.045)$. The CB-only group had a tendency to be associated with annual AE-COPD $(p=0.088)$, while the BEonly group did not $(p=0.866)$.

\section{Comparison of Mortality According to BE and CB Symptoms}

In total, 63 patients (16.2\%) died during the follow-up period. The most common cause of death was respiratory failure (16 patients). Other causes were pneumonia (11 patients), lung cancer (8 patients), cancers other than lung cancer (7 patients), myocardial infarction (4 patients), and suicide (1 patient). The cause of death was unclear in 16 patients. As the cause of death 
Table 3 Comparison of Exacerbation and Death of Four Groups

\begin{tabular}{|c|c|c|c|c|c|c|}
\hline Parameter & $\begin{array}{c}\text { Total } \\
(\mathrm{n}=389)\end{array}$ & $\begin{array}{l}B E / C B \\
(n=52)\end{array}$ & $\begin{array}{c}\text { BE-Only } \\
(n=96)\end{array}$ & $\begin{array}{c}\text { CB-Only } \\
(n=77)\end{array}$ & $\begin{array}{c}\text { No } B E / C B \\
(n=164)\end{array}$ & $P$ value \\
\hline History of $A E$ in previous I year & $78(20.1)$ & $16(30.8)^{\mathrm{a}, \mathrm{b}}$ & $14(14.6)$ & $20(26.0)$ & $28(17.0)$ & 0.045 \\
\hline AE-COPD & $239(61.4)$ & $32(61.5)$ & $54(56.3)$ & $50(64.9)$ & $103(62.8)$ & 0.655 \\
\hline Severe AE-COPD & $91(23.4)$ & $15(28.8)$ & $14(14.6)$ & $23(29.3)$ & $39(23.8)$ & 0.077 \\
\hline AE-COPD/year & $1.0 \pm 3.1$ & $1.0 \pm 1.4$ & $1.4 \pm 5.9$ & $0.9 \pm 1.1$ & $0.8 \pm 1.4$ & 0.545 \\
\hline Severe AE-COPD/year & $0.1 \pm 0.6$ & $0.2 \pm 0.4$ & $0.1 \pm 0.3$ & $0.3 \pm 1.1$ & $0.1 \pm 0.3$ & 0.224 \\
\hline Annual exacerbator (AE/year $\geq \mathrm{I})$ & $114(29.3)$ & $2 \mathrm{I}(40.4)^{\mathrm{a}, \mathrm{b}}$ & $23(24.0)$ & $29(37.7)$ & $4 \mid(25.0)$ & 0.037 \\
\hline Frequent exacerbator (AE/year $\geq 2$ or severe $\mathrm{AE}$ ) & $54(13.9)$ & $7(13.5)$ & II (II.5) & II (14.3) & $25(15.2)$ & 0.863 \\
\hline Overall mortality & $63(16.2)$ & $10(19.2)$ & $13(13.5)$ & $12(15.6)$ & $28(17.1)$ & 0.810 \\
\hline
\end{tabular}

Notes: ${ }^{\text {a }} \mathrm{P}$ value $<0.05$ compared $\mathrm{BE}$-only group. ${ }^{\mathrm{b}} \mathrm{P}$ value $<0.05$ compared no $\mathrm{BE} / \mathrm{CB}$ group.

Abbreviations: $\mathrm{BE}$, bronchiectasis; $\mathrm{CB}$, chronic bronchitis; $\mathrm{AE}-\mathrm{COPD}$, acute exacerbation of chronic obstructive pulmonary disease; severe $\mathrm{AE}-\mathrm{COPD}$, hospitalization or visit to $E R$; frequent exacerbator, $\mathrm{AE}-\mathrm{COPD} /$ year $\geq 2$ or severe $\mathrm{AE}-\mathrm{COPD} /$ year $\geq \mathrm{I}$.

was unidentified in $25.4 \%$ of cases, only all-cause mortality was used for survival analysis. Kaplan-Meier survival curve analysis revealed no significant differences in mortality according to $\mathrm{BE}$ and/or CB symptoms (Figure 3). Clinical parameters associated with death were age, BMI, and 6MWD after adjusting other variables, including $\mathrm{FEV}_{1}$, mMRC, frequent exacerbation, and EI (Table 5).

\section{Discussion}

We found that COPD patients with $\mathrm{BE}$ accompanying $\mathrm{CB}$ symptoms (BE/CB group) were significantly associated with acute exacerbation, which was not the case in BE-only, CBonly, or no BE/CB groups. Based on our study, simply investigating symptoms of $\mathrm{CB}$ will improve prediction of prognosis in COPD patients with accompanying $\mathrm{BE}$.

Because $\mathrm{BE}$ is included as one of the comorbidities of COPD in the 2014 GOLD guidelines, ${ }^{1,2}$ accompanying BE

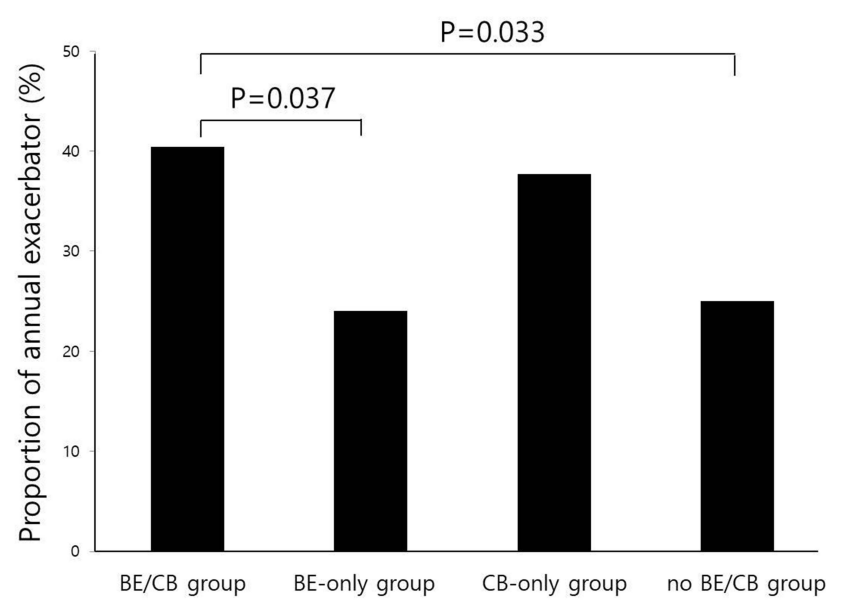

Figure 2 Proportion of annual exacerbators according to the presence of bronchiectasis/chronic bronchitis.

Abbreviations: annual exacerbator, $\mathrm{AE}-\mathrm{COPD} /$ year $\geq \mathrm{I}$; $\mathrm{BE}$, bronchiectasis; $\mathrm{CB}$, chronic bronchitis. has been suggested to be a prevalent and important prognostic marker. We found the presence of BE in as many as $38 \%$ of the patients on chest CT, although we excluded patients showing abnormal findings on chest X-ray, including $\mathrm{BE}$, at the time of enrollment.

$\mathrm{BE}$ is known to be associated with increased risk of exacerbations and mortality in patients with COPD. Recent studies indicated that patients with COPD and BE have increased risk of exacerbations, ${ }^{3,7,8}$ severe airway obstruction, ${ }^{7,8}$ and death. ${ }^{3,6,8,9}$ However, coexisting BE has not always been linked with poorer outcome in COPD patients. ${ }^{10,11}$ Bafadhel et al reported no differences in airway inflammation, exacerbation frequency, or bacterial load in COPD patients with BE. ${ }^{10}$ In a prospective study, Jairam et al also found that the presence of BE was not associated with death or hospitalization due to exacerbation. ${ }^{11}$ In the current study, when we divided the total patient population into two groups according to the presence or absence of BE, we also found no differences between the two groups in terms of exacerbation or mortality. The discrepancies in the results of these studies may be related to the heterogeneity of severity, types, or phenotypes of BE among patient populations. These findings suggest the need for better evaluation of the characteristics of individual patients in addition to the presence of BE, which could lead to individualized optimized treatment.

The severity of BE is often estimated using the Bhalla radiological scoring system, which is known to be correlated with physiological impairment and symptom severity. ${ }^{8,34}$ Cystic BE is associated with poorer prognosis and more severe impairment of $\mathrm{FEV}_{1}$ than other types of BE. ${ }^{35,36}$ In the present study, the median modified Bhalla score of the patients with BE was 9.5 (range: 6.5-14.6), indicating that $\mathrm{BE}$ was less severe than in other studies reporting an association with poor outcome. ${ }^{37}$ Additionally, the most common 
Table 4 Risk Factors Associated with Annual Exacerbation of COPD (Exacerbation /Year $\geq 1$ ) in COPD Patients

\begin{tabular}{|c|c|c|c|c|c|c|}
\hline \multirow[t]{2}{*}{ Parameter $(n=389)$} & \multicolumn{3}{|c|}{ Univariate Analysis } & \multicolumn{3}{|c|}{ Multivariate Analysis $^{a}$} \\
\hline & OR & $95 \% \mathrm{Cl}$ & p-value & OR & $95 \% \mathrm{Cl}$ & $p$-value \\
\hline Age, yr & 1.028 & $0.997-1.060$ & 0.077 & 1.036 & $1.00 \mathrm{I}-1.072$ & 0.046 \\
\hline $\mathrm{BMI}, \mathrm{Kg} / \mathrm{m}^{2}$ & 0.931 & $0.869-0.998$ & 0.042 & 1.004 & $0.92 I-1.094$ & 0.933 \\
\hline Post BD FEV ( (\% predicted) & 0.969 & $0.954-0.983$ & $<0.001$ & 0.984 & $0.965-1.002$ & 0.082 \\
\hline $\mathrm{mMRC}$ & 1.403 & I.I40-1.727 & 0.001 & 1.187 & $0.922-1.530$ & 0.184 \\
\hline 6MWD (m) & 1.000 & $0.997-1.002$ & 0.728 & & & \\
\hline $\mathrm{FEV}$, decline (mL/year) & 1.002 & $0.993-1.011$ & 0.672 & & & \\
\hline The presence of bronchiectasis & 1.034 & $0.660-1.619$ & 1.034 & & & \\
\hline \multicolumn{7}{|l|}{ Type of bronchiectasis } \\
\hline Cylindrical & 0.733 & $0.440-1.220$ & 0.232 & & & \\
\hline Varicose & 1.226 & $0.555-2.708$ & 0.614 & & & \\
\hline Cystic & 0.397 & $0.047-3.333$ & 0.395 & & & \\
\hline Modified Bhalla score & 1.051 & $0.994-1.111$ & 0.078 & & & \\
\hline El (\%) & 1.027 & $1.012-1.043$ & 0.001 & 1.016 & $0.997-1.036$ & 0.094 \\
\hline $\mathrm{Hs}-\mathrm{CRP}(\mathrm{mg} / \mathrm{dL})$ & 0.982 & $0.77|-| .25 \mid$ & 0.883 & & & \\
\hline Blood eosinophils (cells $/ \mu \mathrm{L}$ ) & 1.000 & $0.999-1.001$ & 0.563 & & & \\
\hline Four groups according to $B E, C B$ & & & 0.040 & & & 0.082 \\
\hline No $B E / C B$ group & Reference & & & Reference & & \\
\hline CB-only group & 1.812 & $1.014-3.240$ & 0.045 & 1.764 & $0.919-3.387$ & 0.088 \\
\hline BE-only group & 0.945 & $0.526-1.700$ & 0.851 & 0.945 & $0.491-1.818$ & 0.866 \\
\hline $\mathrm{BE} / \mathrm{CB}$ group & 2.032 & $1.053-3.921$ & 0.034 & 2.110 & $1.016-4.382$ & 0.045 \\
\hline
\end{tabular}

Notes: ${ }^{a}$ Adjusted for age, FEV, BMI, mMRC, El, and four groups according to BE, CB.

Abbreviations: $\mathrm{BD}$, bronchodilator; $\mathrm{FEV}$, forced expiratory volume in I second; BMI, body mass index; mMRC, modified Medical Research Council; 6MWD, 6-minute walk distance; El, emphysema index; hs-CRP, high-sensitivity C-reactive protein; BE, bronchiectasis; $\mathrm{CB}$, chronic bronchitis; OR, odds ratio; Cl, confidential interval.

type of BE was cylindrical, which has been shown to be associated with relatively better lung function and prognosis than other types of $\mathrm{BE} .{ }^{35,36} \mathrm{We}$ analyzed the risk factors for exacerbation/mortality with the modified Bhalla score (data not shown) or type of $\mathrm{BE}$, and found no significant associations.

The presence of chronic infection with pathogenic bacteria or Pseudomonas aeruginosa seems to predict poor prognosis. ${ }^{23,38}$ Again, the presence of chronic infection with Pseudomonas is associated with more severe disease, poorer clinical, functional, and radiological features, and poorer quality of life and long-term outcomes. ${ }^{38}$ Based on cluster analysis, Aliberti et al reported that the "Pseudomonas," "Other chronic infection," and "Daily sputum" clusters had poorer prognosis than the "Dry BE" cluster with the least evidence of chronic infection and no daily sputum and the "Pseudomonas" cluster had the poorest prognosis. ${ }^{23}$
Recently, multimodality indicators, such as the $\mathrm{BE}$ Severity Index (BSI) score and FACED ( $\mathrm{FEV}_{1}$, age, colonization, extension, dyspnea) score, have been developed to effectively evaluate the severity of BE by considering various clinical factors along with radiological findings. ${ }^{39,40}$ Both of these indices also include the presence of chronic bacterial colonization including $P$. aeruginosa. However, these indices and sputum examination are not easily applicable in daily clinical practice.

Practically and theoretically, chronic inflammation of the airways by bacterial colonization causes chronic mucus hypersecretion. ${ }^{41}$ Chronic excessive airway inflammation induced by bacterial infection and colonization is thought to underlie the pathogenesis of $\mathrm{BE}$, and chronic mucus hypersecretion is also considered to be a typical symptom of BE. However, not all patients with BE have cough and/or sputum. ${ }^{23}$ 


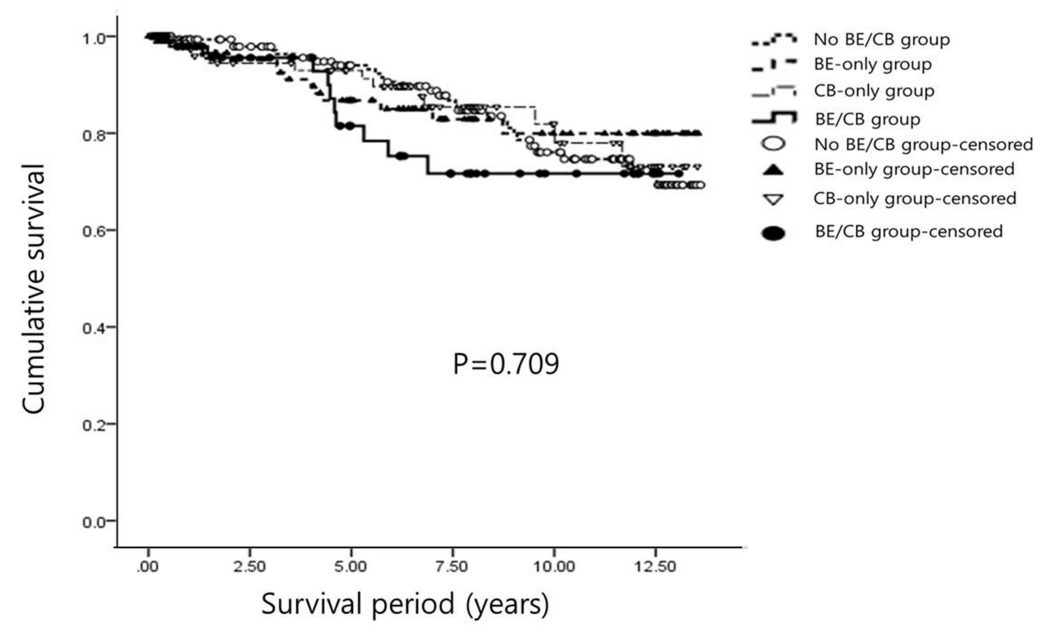

Figure 3 Kaplan-Meier survival analysis among groups. Abbreviations: $\mathrm{BE}$, bronchiectasis; $\mathrm{CB}$, chronic bronchitis.

Previous studies of $\mathrm{BE}$ have reported that isolation of potentially pathogenic microorganisms (PPMs) and/or $P$. aeruginosa was associated with chronic symptoms of cough and sputum. ${ }^{23,38,42}$ Because poor prognostic indicators, including isolation of PPMs and/or P. aeruginosa, are likely to be seen in patients with chronic mucus hypersecretion, ${ }^{23,38,41-43}$ the poor prognosis is also probably related to the $\mathrm{CB}$ symptoms in COPD patients with BE. Chronic bacterial colonization and chronic mucus hypersecretion cannot be thought of separately.

Symptoms of CB have been considered to be important clinical phenotypes and prognostic markers of COPD. ${ }^{12-20}$ $\mathrm{CB}$ is classically defined as chronic cough and sputum production for 3 months/year for at least 2 consecutive years. ${ }^{44}$ Instead of using the classic CB definition, we used the SGRQ CB definition as evidence of chronic mucus hypersecretion. ${ }^{30,31}$

The SGRQ has been used extensively in clinical trials and large cohort studies of COPD, and the SGRQ CB definition has been considered to be $\operatorname{similar}^{30,31}$ or superior $^{45}$ to the classic $\mathrm{CB}$ definition in predicting future exacerbation risk. When we applied the classic definition of $\mathrm{CB}$, only 121 patients responded to the questionnaire and only 52 patients responded they had had symptoms compatible with the definition. The classic CB questionnaire inquires about symptoms for the previous 2 years, and some patients may have difficulty in recalling the details. This may be one of the reasons why the response rate to the classic questionnaire was lower than that of CBrelated questions in SGRQ, which asked about symptoms only for the past 4 weeks.
In the present study, we divided the total patient population into two groups according to $\mathrm{CB}$ symptoms, and found that COPD patients with $\mathrm{CB}$ symptoms were associated with more severe dyspnea and poorer quality of life than those without CB symptoms. This result is consistent with those of previous studies reporting poor prognosis of COPD patients with CB symptoms. ${ }^{12-14}$ Notably, COPD patients with nonsymptomatic BE (BE-only group) had dyspnea and quality of life scores similar to patients in the no $\mathrm{BE} / \mathrm{CB}$ group, indicating that the presence of $\mathrm{BE}$ alone is not clinically significant. Additionally, symptomatic BE with $\mathrm{CB}$ symptoms (BE/CB group) but not $\mathrm{CB}$ alone was the only significant factor for acute exacerbation of COPD in multivariate analysis. These findings suggest that symptomatic $\mathrm{BE}$ has greater clinical significance than $\mathrm{BE}$ per se or $\mathrm{CB}$ symptoms alone (Table 2, Supplementary Table 1, Supplementary Table 2).

To our knowledge, this is the first study to evaluate the significance of combining symptoms of $\mathrm{CB}$ in $\mathrm{COPD}$ patients with BE.

This study had some limitations. First, our cohort included a relatively small number of patients with a significant smoking history recruited only from the pulmonary clinic at a tertiary university hospital, so our results may not fully represent the general COPD population of Korea. Second, we did not examine the sputum microbiology. We regarded that $\mathrm{CB}$ symptoms per se may reflect bacterial colonization to some degree. Colonization by bacteria was shown to be associated with an increase in daily symptoms of CB in COPD patients. ${ }^{41}$ However, from a clinical perspective, sputum surveillance for COPD patients with symptomatic BE is important in developing a better treatment strategy. Lastly, we did not consider 
Table 5 Risk Factors for Mortality by Cox Proportional Hazards Model

\begin{tabular}{|c|c|c|c|c|c|c|}
\hline \multirow[t]{2}{*}{ Parameter $(n=389)$} & \multicolumn{3}{|c|}{ Univariate Analysis } & \multicolumn{3}{|c|}{ Multivariate Analysis $^{a}$} \\
\hline & HR & $95 \% \mathrm{Cl}$ & p-value & HR & $95 \% \mathrm{Cl}$ & $p$-value \\
\hline Age, yr & I.II4 & $1.072-1.158$ & $<0.001$ & $\mathrm{I} .084$ & I.037-I.133 & $<0.001$ \\
\hline Post BD FEV ( (\% predicted) & 0.940 & $0.922-0.958$ & $<0.001$ & 0.978 & $0.956-1.002$ & 0.069 \\
\hline BMI (Kg/m2) & 0.769 & $0.711-0.832$ & $<0.001$ & 0.885 & $0.811-0.966$ & 0.006 \\
\hline $\mathrm{mMRC}$ & 2.037 & $1.592-2.607$ & $<0.001$ & 1.313 & $0.943-1.828$ & 0.107 \\
\hline 6MWD (m) & 0.991 & $0.988-0.993$ & $<0.001$ & 0.996 & $0.993-1.000$ & 0.030 \\
\hline $\mathrm{FEV}_{\text {, decline (mL/year) }}$ & 1.008 & $0.998-1.017$ & 0.115 & & & \\
\hline Frequent exacerbation & 3.582 & $2.105-6.095$ & $<0.001$ & 1.725 & $0.927-3.208$ & 0.085 \\
\hline El (\%) & 1.048 & $1.031-1.065$ & $<0.001$ & 1.013 & $0.993-1.033$ & 0.193 \\
\hline The presence of bronchiectasis & 1.143 & $0.684-1.910$ & 0.610 & & & \\
\hline $\mathrm{Hs}-\mathrm{CRP}(\mathrm{mg} / \mathrm{dL})$ & 1.098 & $0.938-1.285$ & 0.247 & & & \\
\hline Blood eosinophils (cells $/ \mu \mathrm{L}$ ) & 1.000 & $0.999-1.001$ & 0.758 & & & \\
\hline Four groups according to $B E, C B$ & & & 0.710 & & & \\
\hline No $B E / C B$ group & Reference & & & & & \\
\hline CB-only group & 0.947 & $0.48 I-1.863$ & 0.846 & & & \\
\hline BE-only group & 0.956 & $0.495-1.846$ & 0.720 & & & \\
\hline $\mathrm{BE} / \mathrm{CB}$ group & 1.458 & $0.707-3.006$ & 0.307 & & & \\
\hline
\end{tabular}

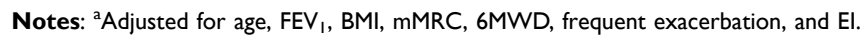

Abbreviations: $\mathrm{BD}$, bronchodilator; $\mathrm{FEV}_{1}$, forced expiratory volume in I second; BMI, body mass index; mMRC, modified Medical Research Council; 6MWD, 6-minute walk distance; frequent exacerbation, $>2$ exacerbation or >I admission to hospital or visiting the emergency department/year; El, emphysema index; hs-CRP, high-sensitivity C-reactive protein; $\mathrm{BE}$, bronchiectasis; $\mathrm{CB}$, chronic bronchitis; $\mathrm{HR}$, hazard ratio; $\mathrm{Cl}$, confidential interval.

airway inflammatory markers. Increased airway inflammatory markers such as sputum eosinophil numbers and sputum IL-1b are associated with the subset of COPD exacerbations. ${ }^{46}$ Recent reports have shown that the measurement of blood eosinophils is comparable to that of airway eosinophils. ${ }^{47} \mathrm{We}$ measured blood eosinophil count as a marker of eosinophilic airway inflammation and found no association with exacerbation.

\section{Conclusion}

$\mathrm{BE}$ accompanying $\mathrm{CB}$ symptoms is associated with $\mathrm{AE}-$ COPD, while non-symptomatic BE is not significantly associated. Symptomatic BE is more important for predicting prognosis than the presence of BE per se in COPD patients. These results suggest that it is more important to identify symptoms of BE to predict acute exacerbation than simply detecting the presence of BE in COPD patients.

\section{Abbreviations}

COPD, chronic obstructive pulmonary disease; BE, bronchiectasis; CB, chronic bronchitis; SGRQ, St. George
Respiratory Questionnaire; AE-COPD, acute exacerbation of $\mathrm{COPD} ; \mathrm{FEV}_{1}$, forced expiratory volume in 1 second; FVC, forced vital capacity; BMI, body mass index; mMRC, Modified Medical Research Council; 6MWD, 6-minute walk distance; hs-CRP, high-sensitivity C-reactive protein; EI, emphysema index; AWA\%, airway wall area percentage; ATI, air-trapping index; ICS, inhaled corticosteroid; LABA, long-acting $\beta 2$-agonist; LAMA, long-acting muscarinic antagonist.

\section{Acknowledgment}

We authors thank the members of the KOLD Study Group for the provision of the KOLD Cohort data (Obstructive Lung Disease Research Foundation http://www.oldrf.org).

Prof. Sang-Do Lee, Prof. Yeon-Mok Oh, Prof. Jin Won Huh, Prof. Seung Won Ra, Prof. Jae Seung Lee, Prof. Sei Won Lee (Univ. of Ulsan), Prof. Deog Kyeom Kim, Prof. Sang-Min Lee, Prof. Ho Il Yoon (Seoul National Univ.), Prof. Tae-Hyung Kim, Prof. Sang-Heon Kim (Hanyang Univ.), Prof. Young Sam Kim, Prof. Prof. Won Yeon Lee (Yonsei Univ.), Prof. Woo Jin Kim (Kangwon National Univ.), Prof. Hye Kyeong 
Park, Prof. Sung-Soon Lee (Inje Univ.), Prof. Ji-Hyun Lee, Prof. Eun Kyung Kim (Bundang CHA Hospital), Prof. Jin Hwa Lee (Ewha Womans Univ.), Prof. Sang Yeub Lee (Korea Univ.), Prof. Seong Yong Lim, Prof. Hye Yun Park (Sungkyunkwan Univ.), Prof. Tae Rim Shin, Prof. Yong Il Hwang, Prof. Yong Bum Park (Hallym Univ.), Prof. Seung Soo Sheen, Joo Hun Park (Ajou Univ.), Prof. Prof. Kwang Ha Yoo (Konkuk Univ.), Prof. Yee Hyung Kim (Kyung Hee Univ.) and Prof. Chin Kook Rhee (Catholic Univ.).

\section{Author Contributions}

All authors made a significant contribution to the work reported, whether that is in the conception, study design, execution, acquisition of data, analysis and interpretation, or in all these areas; took part in drafting, revising or critically reviewing the article; gave final approval of the version to be published; have agreed on the journal to which the article has been submitted; and agree to be accountable for all aspects of the work.

\section{Disclosure}

The authors declare that they have no conflicts of interest for this work.

\section{References}

1. Vogelmeier CF, Criner GJ, Martinez FJ, et al. Global strategy for the diagnosis, management, and prevention of chronic obstructive lung disease 2017 report. GOLD executive summary. Am J Respir Crit Care Med. 2017;195(5):557-582. doi:10.1164/rccm.201701-0218PP

2. From the global strategy for the diagnosis, management and prevention of COPD, global initiative for chronic obstructive lung disease (GOLD); 2021. Available from: http://goldcopd.org. Accessed October 19, 2021.

3. Martinez-Garcia MA, de la Rosa Carrillo D, Soler-Cataluna JJ, et al. Prognostic value of bronchiectasis in patients with moderate-to-severe chronic obstructive pulmonary disease. Am J Respir Crit Care Med. 2013;187(8):823-831. doi:10.1164/rccm.201208-1518OC

4. Patel IS, Vlahos I, Wilkinson TM, et al. Bronchiectasis, exacerbation indices, and inflammation in chronic obstructive pulmonary disease Am J Respir Crit Care Med. 2004;170(4):400-407. doi:10.1164/ rccm.200305-648OC

5. Du Q, Jin J, Liu X, Sun Y. Bronchiectasis as a comorbidity of chronic obstructive pulmonary disease: a systematic review and meta-analysis. PLoS One. 2016;11(3):e0150532. doi:10.1371/journal.pone.0150532

6. Gatheral T, Kumar N, Sansom B, et al. COPD-related bronchiectasis; independent impact on disease course and outcomes. COPD. 2014;11 (6):605-614. doi:10.3109/15412555.2014.922174

7. Martinez-Garcia MA, Soler-Cataluna JJ, Donat Sanz Y, et al. Factors associated with bronchiectasis in patients with COPD. Chest. 2011;140 (5):1130-1137. doi:10.1378/chest.10-1758

8. Tulek B, Kivrak AS, Ozbek S, Kanat F, Suerdem M. Phenotyping of chronic obstructive pulmonary disease using the modified Bhalla scoring system for high-resolution computed tomography. Can Respir J. 2013;20:91-96.
9. Mao B, Lu H-W, Li M-H, et al. The existence of bronchiectasis predicts worse prognosis in patients with COPD. Sci Rep. 2015;5 (1):1-9. doi:10.1038/srep10961

10. Bafadhel M, Umar I, Gupta S, et al. The role of CT scanning in multidimensional phenotyping of COPD. Chest. 2011;140 (3):634-642. doi:10.1378/chest.10-3007

11. Jairam PM, van der Graaf Y, Lammers JW, Mali WP, de Jong PA. Incidental findings on chest $\mathrm{CT}$ imaging are associated with increased COPD exacerbations and mortality. Thorax. 2015;70(8):725-731. doi:10.1136/thoraxjnl-2014-206160

12. de Oca MM, Halbert RJ, Lopez MV, et al. The chronic bronchitis phenotype in subjects with and without COPD: the PLATINO study. Eur Respir J. 2012;40(1):28-36. doi:10.1183/09031936.00141611

13. Kim V, Zhao H, Boriek AM, et al. Persistent and newly developed chronic bronchitis are associated with worse outcomes in chronic obstructive pulmonary disease. Ann Am Thorac Soc. 2016;13 (7):1016-1025. doi:10.1513/AnnalsATS.201512-800OC

14. Kim V, Sternberg AL, Washko G, et al. Severe chronic bronchitis in advanced emphysema increases mortality and hospitalizations. COPD. 2013;10(6):667-678. doi:10.3109/15412555.2013.827166

15. Sherman CB, Xu X, Speizer FE, Ferris BG Jr, Weiss ST, Dockery DW. Longitudinal lung function decline in subjects with respiratory symptoms. Am Rev Respir Dis. 1992;146:855-859. doi:10.1164/ajrccm/146.4.855

16. Vestbo J, Prescott E, Lange P. Association of chronic mucus hypersecretion with FEV1 decline and chronic obstructive pulmonary disease morbidity. Copenhagen City Heart Study Group. Am J Respir Crit Care Med. 1996;153(5):1530-1535. doi:10.1164/ajrccm.15 3.5.8630597

17. James A, Wenzel S. Clinical relevance of airway remodelling in airway diseases. Eur Respir J. 2007;30(1):134-155. doi:10.1183/ 09031936.00146905

18. Pelkonen M, Notkola I-L, Nissinen A, Tukiainen H, Koskela H. Thirty-year cumulative incidence of chronic bronchitis and COPD in relation to 30-year pulmonary function and 40-year mortality: a follow-up in middle-aged rural men. Chest. 2006;130(4):1129-1137. doi:10.1378/chest.130.4.1129

19. Guerra S, Sherrill DL, Venker C, Ceccato CM, Halonen M, Martinez FD. Chronic bronchitis before age 50 years predicts incident airflow limitation and mortality risk. Thorax. 2009;64 (10):894-900. doi:10.1136/thx.2008.110619

20. Kim V, Han MK, Vance GB, et al. The chronic bronchitic phenotype of COPD: an analysis of the COPDGene Study. Chest. 2011;140 (3):626-633. doi:10.1378/chest.10-2948

21. Lindberg A, Eriksson B, Larsson L-G, Rönmark E, Sandström T, Lundbäck B. Seven-year cumulative incidence of COPD in an age-stratified general population sample. Chest. 2006;129 (4):879-885. doi:10.1378/chest.129.4.879

22. De Marco R, Accordini S, Cerveri I, et al. Incidence of chronic obstructive pulmonary disease in a cohort of young adults according to the presence of chronic cough and phlegm. Am J Respir Crit Care Med. 2007;175(1):32-39. doi:10.1164/rccm.200603-381OC

23. Aliberti S, Lonni S, Dore S, et al. Clinical phenotypes in adult patients with bronchiectasis. Eur Respir J. 2016;47(4):1113-1122. doi:10.1183/13993003.01899-2015

24. Mahler DA, Wells CK. Evaluation of clinical methods for rating dyspnea. Chest. 1988;93(3):580-586. doi:10.1378/chest.93.3.580

25. Jones PW, Quirk FH, Baveystock CM, Littlejohns P. A self-complete measure of health status for chronic airflow limitation. Am Rev Respir Dis. 1992;145(6):1321-1327. doi:10.1164/ajrccm/145.6.1321

26. Standardization of Spirometry, 1994 Update. American Thoracic Society. Am J Respir Crit Care Med. 1995;152(3):1107-1136.

27. Lee YK, Oh YM, Lee JH, et al. Quantitative assessment of emphysema, air trapping, and airway thickening on computed tomography. Lung. 2008;186(3):157-165. doi:10.1007/s00408-008-9071-0 
28. Naidich DP, McCauley DI, Khouri NF, Stitik FP, Siegelman SS. Computed tomography of bronchiectasis. J Comput Assist Tomogr. 1982;6(3):437-444. doi:10.1097/00004728-198206000-00001

29. Bhalla M, Turcios N, Aponte V, et al. Cystic fibrosis: scoring system with thin-section CT. Radiology. 1991;179(3):783-788. doi:10.1148/ radiology.179.3.2027992

30. Kim V, Crapo J, Zhao H, et al. Comparison between an alternative and the classic definition of chronic bronchitis in COPDGene. Ann Am Thorac Soc. 2015;12(3):332-339. doi:10.1513/AnnalsATS.2 01411-518OC

31. Lim JU, Lee J-H, Kim T-H, et al. Alternative definitions of chronic bronchitis and their correlation with CT parameters. Int $J$ Chron Obstruct Pulmon Dis. 2018;13:1893. doi:10.2147/COPD.S164055

32. Wedzicha JA, Seemungal TA. COPD exacerbations: defining their cause and prevention. Lancet. 2007;370(9589):786-796. doi:10.1016/ S0140-6736(07)61382-8

33. Kim J, Yoon HI, Oh YM, et al. Lung function decline rates according to GOLD group in patients with chronic obstructive pulmonary disease. Int J Chron Obstruct Pulmon Dis. 2015;10:1819-1827. doi:10.2147/COPD.S87766

34. Metersky ML. The initial evaluation of adults with bronchiectasis. Clin Chest Med. 2012;33(2):219-231. doi:10.1016/j.ccm.201 2.03.004

35. Perry KM, King DS. Bronchiectasis: a study of prognosis based on a follow-up of 400 patients. Am Rev Tuberc. 1940;41(5):531-548.

36. O’Brien C, Guest P, Hill S, Stockley R. Physiological and radiological characterisation of patients diagnosed with chronic obstructive pulmonary disease in primary care. Thorax. 2000;55(8):635-642. doi:10.1136/thorax.55.8.635

37. Dakin CJ, Pereira JK, Henry RL, Wang H, Morton JR. Relationship between sputum inflammatory markers, lung function, and lung pathology on high-resolution computed tomography in children with cystic fibrosis. Pediatr Pulmonol. 2002;33(6):475-482. doi:10.1002/ppul.10109

38. Finch S, McDonnell MJ, Abo-Leyah H, Aliberti S, Chalmers JD. A comprehensive analysis of the impact of Pseudomonas aeruginosa colonization on prognosis in adult bronchiectasis. Ann Am Thorac Soc. 2015;12(11):1602-1611.
39. Martínez-García MÁ, De Gracia J, Relat MV, et al. Multidimensional approach to non-cystic fibrosis bronchiectasis: the FACED score. Eur Respir J. 2014;43(5):1357-1367. doi:10.1183/09031936.00026313

40. Chalmers JD, Goeminne P, Aliberti S, et al. The bronchiectasis severity index: an international derivation and validation study. $\mathrm{Am}$ $J$ Respir Crit Care Med. 2014;189(5):576-585. doi:10.1164/ rccm.201309-1575OC

41. Desai H, Eschberger K, Wrona C, et al. Bacterial colonization increases daily symptoms in patients with chronic obstructive pulmonary disease. Ann Am Thorac Soc. 2014;11(3):303-309. doi:10.1513/AnnalsATS.201310-350OC

42. Kwok WC, Ho JCM, Tam TCC, Ip MSM, Lam DCL. Risk factors for Pseudomonas aeruginosa colonization in non-cystic fibrosis bronchiectasis and clinical implications. Respir Res. 2021;22(1):132. doi:10.1186/s12931-021-01729-5

43. Banerjee D, Khair O, Honeybourne D. Impact of sputum bacteria on airway inflammation and health status in clinical stable COPD. Eur Respir J. 2004;23(5):685-691. doi:10.1183/09031936.04.00056804

44. Ferris B. Epidemiology standardization project (American Thoracic Society): recommended respiratory disease questionnaires for use with adult and children in epidemiological research. Am Rev Respir Dis. 1978;118:7-53.

45. Kim V, Zhao H, Regan E, et al. The St. George's Respiratory Questionnaire definition of chronic bronchitis may be a better predictor of COPD exacerbations compared with the classic definition. Chest. 2019;156(4):685-695. doi:10.1016/j.chest.2019.03.041

46. Bafadhel M, McKenna S, Terry S, et al. Acute exacerbations of chronic obstructive pulmonary disease: identification of biologic clusters and their biomarkers. Am J Respir Crit Care Med. 2011;184(6):662-671. doi:10.1164/rccm.201104-0597OC

47. Bafadhel M, McKenna S, Terry S, et al. Blood eosinophils to direct corticosteroid treatment of exacerbations of chronic obstructive pulmonary disease: a randomized placebo-controlled trial. Am J Respir Crit Care Med. 2012;186(1):48-55. doi:10.1164/rccm.201108$1553 \mathrm{OC}$

\section{Publish your work in this journal}

The International Journal of COPD is an international, peer-reviewed journal of therapeutics and pharmacology focusing on concise rapid reporting of clinical studies and reviews in COPD. Special focus is given to the pathophysiological processes underlying the disease, intervention programs, patient focused education, and self management protocols. This journal is indexed on PubMed Central, MedLine and CAS. The manuscript management system is completely online and includes a very quick and fair peer-review system, which is all easy to use. Visit http://www.dovepress.com/testimonials.php to read real quotes from published authors.

Submit your manuscript here: https://www.dovepress.com/international-journal-of-chronic-obstructive-pulmonary-disease-journal 